\title{
Anxiety and depression in twin and sib pairs extremely discordant and concordant for neuroticism: prodromus to a linkage study
}

\author{
Katherine M Kirk ${ }^{1}$, Andrew JBirley ${ }^{1}$, Dixie JStatham ${ }^{1}$, Barbara Haddon ${ }^{1}$, Robert IE Lake ${ }^{1}$, \\ J Gavin Andrews ${ }^{2}$ and Nicholas G Martin ${ }^{1}$ \\ ${ }^{1}$ Queensland Institute of Medical Research and Joint Genetics Program, University of Queensland, Brisbane \\ ${ }^{2}$ World Health Organization Collaborating Centre for Medical Health and Substance Abuse, St Vincent's Hospital, \\ Sydney, Australia
}

\begin{abstract}
Multivariate modelling of anxiety and depression data in twins has suggested that the two phenotypes are largely underpinned by one genetic factor, while other studies have indicated a relationship between these disorders and the neuroticism personality trait. As part of a study to identify quantitative trait loci for anxiety and depression, questionnaire responses and interviews of 15027 Australian twins and 11389 of their family members conducted during the past 20 years were reviewed to identify individuals with neuroticism, anxiety and depression scores in the upper or lower deciles of the population. This information was then used to identify extreme discordant and concordant (EDAC) sib pairs. 1373high-scoring and 1571low-scoring subjects (2357 sib pairs) were selected for participation, and extremely high participation rates were achieved, with over $90 \%$ of contactable prospective participants completing the interview phase, and over $90 \%$ of these providing blood or buccal samples. Participation bias arising from the nature of the selection variables was minimal, with only a small difference between rates of interview participation among prospective participants with high and low selection scores $(89.4 \%$ vs $91.6 \%$ ). The interview permitted the diagnosis of depression and several anxiety disorders (OCD, agoraphobia, panic disorder, generalised anxiety disorder) in this sample according to DSM-IV criteria. The methodology for selection of prospective subjects was demonstrated to be extremely successful, with highly significant differences in depression and anxiety disorder prevalence rates between individuals in the two selection groups. The success of this EDAC sampling scheme will enhance the power for QTL linkage and association analysis in this sample. Twin Research (2000) 3, 299-309.
\end{abstract}

Keywords: anxiety, depression, twins, sib pairs, selected sample, EDAC

\section{Introduction}

A number of studies ${ }^{1-7}$ have demonstrated that anxiety and depression share the same genetic factors influencing their development, but are subject to predominantly distinct environmental factors. The personality trait of neuroticism ${ }^{8}$ has also been found to be largely dependent on the same genes as anxiety and depression, ${ }^{1}$ as has psychological distress. ${ }^{9}$

Studies of other disorders such as agoraphobia and social phobia, ${ }^{4,10}$ have indicated that these al so have a common genetic basis, with some studies ${ }^{11,12}$ indicating that phobias and panic disorder may be influenced by a genetic factor separate from that

Correspondence: Dr KM Kirk, Queensland Institute of Medical Research, Post Office, Royal Brisbane Hospital, Brisbane QLD 4029, Australia. Tel: + 6173362 0272; Fax: +6173362 0101; E-mail: kathE@gimr.edu.au

Received 4 May 2000; revised 8 September 2000; accepted 8 September 2000 affecting anxiety and depression. How ever, evidence for genetic influences common to generalised anxiety disorder and panic disorder has since been reported. ${ }^{13}$

Given the multitude of studies reporting comorbidity of various combinations of these disorders, along with the evidence of common genetic influences from numerous twin and family studies, it has been hypothesised that there may be a set of genes that predisposes individuals to the group of disorders mentioned above, with different environmental stressors leading to the development of the various observed forms of psychopathology. ${ }^{14}$ In order to start searching for these genes, we reviewed interview and self-report questionnaire data collected from adult Australian twins and their immediate family members over the previous 20 years. Individuals who were members of sib pairs at the extremes for discordance or concordance (EDAC) on measures of neuroticism, anxiety and depression were identified ${ }^{15,16}$ in order to maximise 
the power to detect linkage for a given amount of genotyping. ${ }^{17}$ This paper outlines the methods used in the recruitment of subjects and collection of follow-up phenotypic information. It also provides preliminary results supporting our initial hypothesis.

\section{Methods}

\section{Selection of study participants}

Self-report questionnaire and/or interview data were available on 15027 twin individuals (including 6888 complete pairs) and 11389 of their family members over the period 1980-1995, as summarised in Table1. The twins participating in this study were all recruited from the Australian Twin Registry, a volunteer register begun in 1978 which has about 27000 pairs of twins enrolled and in various stages of active contact. Two separate cohorts of twins were identified: those born prior to 1965 (Cohort 1), and those born between 1964 and 1970 (Cohort 2).

Twins Twins in Cohort 1 were originally contacted via a self-report Health and Lifestyle Questionnaire mailed in 1980-1982 to all twin pairs over 18 years of age who were registered with the Australian Twin Registry (5867 pairs). This questionnaire contained the full 90-item Eysenck Personality Questionnaire (EPQ), ${ }^{8}$ including a 23-item Neuroticism, scale, as well as the scales of anxiety and depression from the Delusion Symptom States Inventory (DSSI/sAD). ${ }^{18}$ Responses were obtained from 3808 complete twin pairs and 576 singles.

A follow-up questionnaire was mailed to the individuals who participated in the original survey (and their co-twins for incomplete twin pairs) during 1988-1990, with responses received from 3051 complete pairs and 468 singles. This second question- naire included the short form of the EPQ-R, ${ }^{19}$ with a 12-item Neuroticism scale, al ong with the DSSI/SAD scales. A 19-item subset of the SCL- $90^{20}$ was included, with the selection focusing on items that pertained to recently experienced psychiatric distress (depression, anxiety, phobic anxiety, somatic distress and insomnia). A similar questionnaire was mailed in 1990 to the twins identified in Cohort 2 (ie those born between 1964 and 1970), with responses from 2270 complete pairs and a further 518 singles (a response rate of $83 \%$ from those contactable). ${ }^{21}$

From 1993 to 1995, a telephone-based semistructured interview designed to assess the physical, psychological and social manifestations of alcoholism and related disorders (SSAGA-OZ) was administered to a subset of the twins from Cohort 1 (2456twin pairs and 771 individuals). Among a variety of other measures, it included items leading to diagnoses of DSM-IIIR major depression and panic disorder. Around the same time, a group of twins aged over 50 were recruited for a Health and Lifestyle questionnaire-based study specifically targeted at the health problems faced by older people. Approximately $50 \%$ of the sample for this study were from Cohort 1; the remainder were twins who had registered with the Australian Twin Registry since 1982 and had not previously participated in any of our studies. Of the $2281 \mathrm{twin}$ pairs approached, responses were obtained from 1279 complete pairs and a further 558 singles.

Family members As part of the questionnaires sent out to each cohort from 1988 to 1990, twins were requested to fill in contact details for family members aged over 18 years who would be prepared to receive similar questionnaires. Slightly modified versions of the twin questionnaires were then sent to parents, adult siblings, spouses and adult children of twins identified in these questionnaire responses. The overall response rate from relatives approached

Table1 Participation by twinsand their relativesin Heal th and Lifestyle Questionnai resand tel ephone-based interview studies, 1980-1995

\begin{tabular}{|c|c|c|c|c|c|c|c|c|}
\hline Year & Contact type & Measures & $\begin{array}{l}\text { Twins } \\
\text { (Cohort 1) }\end{array}$ & $\begin{array}{l}\text { Twins } \\
\text { (Cohort 2) }\end{array}$ & $\begin{array}{l}\text { Non-twin } \\
\text { siblings }\end{array}$ & $\begin{array}{l}\text { Adult } \\
\text { children } \\
\text { of twins }\end{array}$ & $\begin{array}{l}\text { Parents } \\
\text { of } \\
\text { twins }\end{array}$ & $\begin{array}{l}\text { Spouses } \\
\text { of twins }\end{array}$ \\
\hline $\begin{array}{l}1980- \\
1982\end{array}$ & $\begin{array}{l}\text { Heal th and Lifestyle } \\
\text { Questionnaire }\end{array}$ & $\begin{array}{l}\text { EPQ Neuroticism } \\
\text { DSSI/SAD }\end{array}$ & $\begin{array}{l}3808 \text { pairs } \\
576 \text { singles }\end{array}$ & & & & & \\
\hline $\begin{array}{l}1989- \\
1990\end{array}$ & $\begin{array}{l}\text { Health and Lifestyle } \\
\text { Questionnaire }\end{array}$ & $\begin{array}{l}\text { EPQ-R Neuroticism (short scale) } \\
\text { DSSI/SAD, } 19 \text { SCL-90 items }\end{array}$ & $\begin{array}{l}3051 \text { pairs } \\
468 \text { singles }\end{array}$ & & & & & \\
\hline 1990 & $\begin{array}{l}\text { Heal th and Lifestyle } \\
\text { Questionnaire }\end{array}$ & $\begin{array}{l}\text { EPQ-R Neuroticism (short scale) } \\
\text { DSSI/SAD, } 19 \text { SCL-90 items }\end{array}$ & & $\begin{array}{l}2270 \text { pairs } \\
518 \text { singles }\end{array}$ & & & & \\
\hline $\begin{array}{l}1989- \\
1992\end{array}$ & $\begin{array}{l}\text { Health and Lifestyle } \\
\text { Questionnaire }\end{array}$ & EPQ-R Neuroticism (short scale) & & & $\begin{array}{l}3715 \\
\text { siblings }\end{array}$ & $\begin{array}{l}1660 \\
\text { children }\end{array}$ & $\begin{array}{l}3570 \\
\text { parents }\end{array}$ & $\begin{array}{l}2444 \\
\text { spouses }\end{array}$ \\
\hline $\begin{array}{l}1993- \\
1995\end{array}$ & $\begin{array}{l}\text { SSAGA-OZ } \\
\text { tel ephone interview }\end{array}$ & $\begin{array}{l}\text { DSM-IIIR depression, } \\
\text { panic disorder }\end{array}$ & $\begin{array}{l}2456 \text { pairs } \\
771 \text { singles }\end{array}$ & & & & & \\
\hline $\begin{array}{l}1993- \\
1995\end{array}$ & $\begin{array}{l}\text { Health and Lifestyle } \\
\text { Questionnaire (age > 50) }\end{array}$ & $\begin{array}{l}\text { EPQ-R Neuroticism (short scale) } \\
\text { DSSI/sAD }\end{array}$ & $\begin{array}{l}1279 \text { pairs } \\
558 \text { singles }\end{array}$ & & & & & \\
\hline
\end{tabular}


was $59 \%$, with responses from 3570 parents, 3715 siblings, 2444 spouses and 1660 children of the twin probands.

\section{Selection procedures}

Carey and Williamson ${ }^{22}$ showed that selecting siblings through an extreme proband increased statistical power, while Eaves and Meyer ${ }^{15}$ and Risch and Zhang $^{16}$ showed that extreme discordant sibling pairs carried more information per pair than other sibling pairs, followed by extreme concordant sibling pairs. They also showed that intermediate pairs carried little information, and hence little power to detect linkage. Gu, Todorov, and Rao ${ }^{17}$ al so showed the increase in power from including extremely concordant pairs. The question of determining the best sampling strategy from a fixed size population of sibling pairs, in order to maximise the power to detect linkage between a marker and a putative quantitative trait locus (QTL), has been reconsidered by Lake. ${ }^{23}$ The approach was used to simulate a QTL under a range of conditions of gene action and allele frequencies, and then to determine the most informative cells when the pairs are cross-classified by deciles on the phenotypic distribution. Simple additive action $(d=0)$, complete dominance $(d=a)$, and complete recessiveness $(d=-a)$ were simulated with a range of allele frequencies (additive cases: $P=0.2,0.4,0.6,0.8$; dominant cases: $P=0.2,0.4$, 0.5 ; recessive cases: $P=0.5,0.6,0.8)$. These results were then aggregated to give a picture of the information surface across all ten gene action/allele frequency combinations. The information surface is the plane $f(x, y, z)$ where $(x, y)$ is the bivariate sibling pair distribution and $z$ is the informativeness of each $(x, y)$ combination. The contours demonstrate the optimal sibling pair selection strategy, as shown in Figure 1. Maximum information is gained from the $[1,10]$ and $[10,1]$ (extreme discordant) cells, while the cells on the edge and adjacent to the extreme discordant cells (ie [1,9], [2,10], [9,1], and [10,2]) are as informative as the extreme concordant cells $([1,1]$ and $[10,10])$.

Identification of prospective study participants occurred in three waves, with the objective of identifying sibships providing the maximum genetic information for the traits of interest as outlined above. In total, relevant information was available for 13309 members of twin pairs, 3644 non-siblings

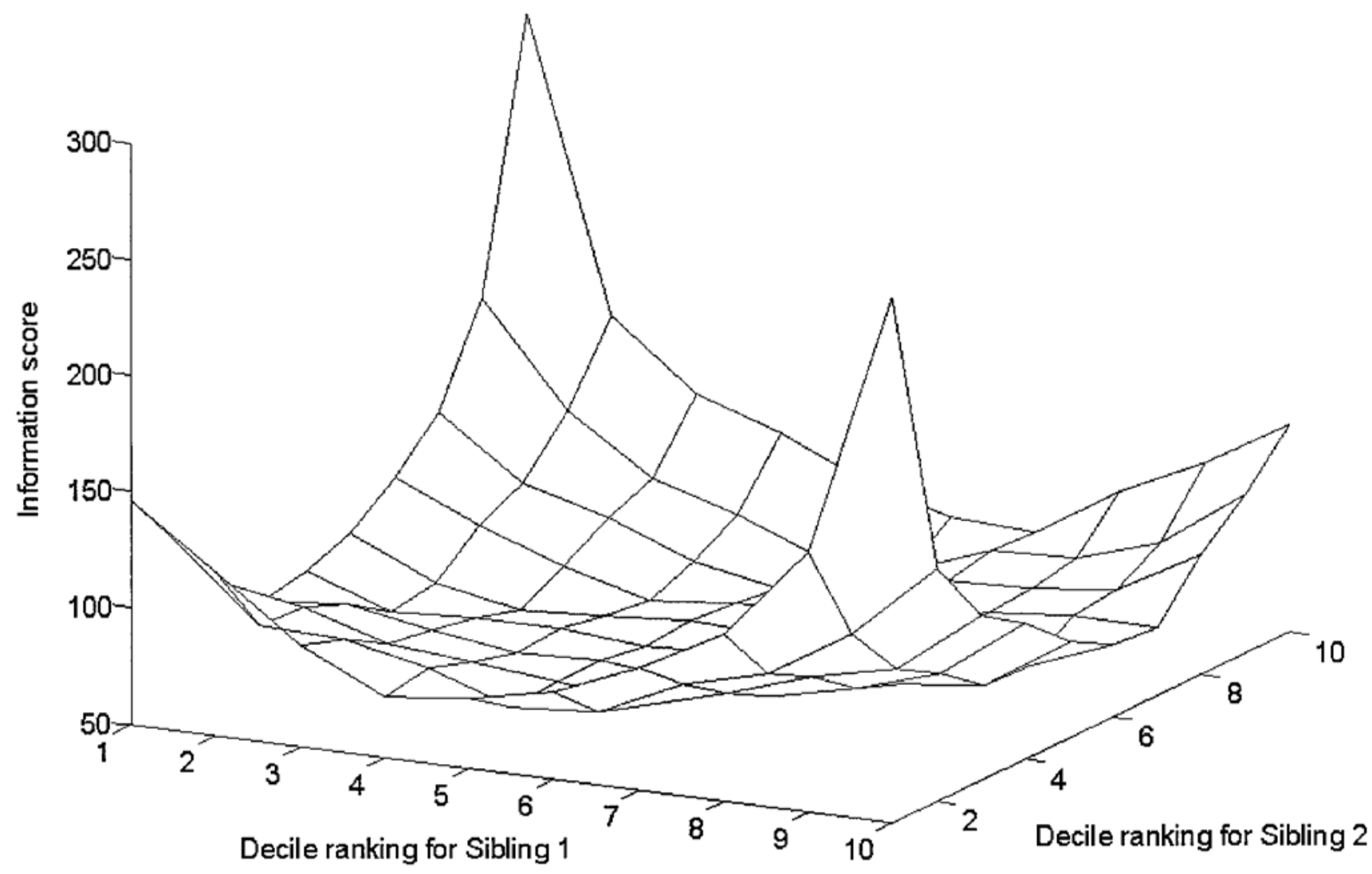

Figure 1 Information score (1/variance of estimate) for the combined additive cases $(P=0.2,0.4,0.6,0.8)$, dominant cases $(P=0.2,0.4$, $0.5)$, and recessive cases $(P=0.5,0.6,0.8), n=1000$ replications 
of twins, and 1625 children of twins (18578 individuals in all). Initial selection was based on the 12-item Neuroticism scale from the revised short form of the Eysenck Personality Questionnaire, ${ }^{19}$ as it was present in all of the self-report questionnaires mailed to twins and their family members during this time. It is also as a subset of the full 23-item Neuroticism scale in the original questionnaire sent to Cohort 1 twins.

For the first wave of selection, short-scale EPQ-R Neuroticism scores were calculated for all twins, siblings of twins and children of twins who participated in the studies conducted between 1988 and 1991. An arcsine transformation was applied to the Neuroticism scores to improve the approximation of a normal distribution. The transformed scores were corrected for regression on age, sex, $\mathrm{age}^{2}$, and the age $\times$ sex and age $^{2} \times$ sex interaction terms, and the residuals ranked into deciles. Individuals who returned rankings within the lowest or highest decile for any of the studies conducted between 1989 and 1991 were selected, and extreme concordant and discordant sib pairs were identified. Only those individuals who were members of at least one concordant or discordant sib pair were added to the list of prospective subjects. This phase identified 1101 prospective participants from 490 families: 531 with EPQ-R short scale Neuroticism residual scores ranked in the highest decile, and 570 with scores in the lowest decile, making 735 potential sib pairs in total.

Selection for Wave 2 participants was based on similar criteria to Wave1, except that individuals who had short-scale EPQ-R Neuroticism residual scores in the second lowest and second highest deciles were also included on the condition that a concordant or discordant pair could be made with at least one sibling who had a residual score in the first or tenth decile (in line with our identification of $[1,9],[2,10],[9,1]$ and [10,2] pairs as next most informative). This al so acted to increase the number of eligible individuals in the lowest and highest deciles, since more of them could form eligible sib pairs. An additional 1068 individuals were identified for prospective inclusion in the study, consisting of 267 in the lowest decile (Decile 1), 292 in the second lowest decile (Decile2), 283 in the second highest decile (Decile9), and 226 in the highest decile (Decile 10). This added an extra 918 sib pairs to the list of potential participants.

Criteria for inclusion in Wave 3 differed from the previous waves, in that a larger number of variables was used in the selection procedure. In addition to short-scale EPQ-R Neuroticism scores used previously, other measures of Neuroticism (including full scale EPQ Neuroticism scores recorded in the Health and Lifestyle Questionnaire in 1980-1982), anxiety, depression and somatic distress were available over a period of up to 15 years, as shown in Table1. DSM-IIIR diagnoses for panic disorder and depression from the SSAGA study were al so incorporated. Since approximately half of the older twins from the Over 50s questionnaire had not previously been included in the previous questionnaire and interview studies, these twin pairs were added to the list of prospective study participants.

In order to combine the information on each individual from the various questionnaire and interview waves and measures, normal scores were calculated for each scale, and corrected for regression on age, sex, $a^{2} e^{2}$, and the age by sex and $a^{2} e^{2}$ by sex interaction terms. The mean of all available residual scores was then calculated for each person, and decile rankings calculated on this mean value. Members of the uppermost and lowermost quintiles who could form extreme concordant or discordant sib pairs with other individuals in any of the three waves were then identified, subject to the continuing conditions that every family must have at least one member of the uppermost or lowermost decile.

It is important to note that Wave 3 was supplementary to Waves 1 and 2, meaning that no individuals selected in previous waves was excluded from the study on the basis of their Wave 3 rankings. As information available on non-twin relatives of twins in Wave 3 was no greater than for Waves 1 and 2, no change in decile rankings occurred for these individuals. However, new rankings were obtained for a substantial number of twins, creating new eligible sib pairs among twins and their siblings. The degree of change in the rankings for these twins was not great, with a polychoric correlation of 0.95 between their rankings under the two scoring systems. 775 individuals were selected in Wave 3: 222 in the first decile, 220 in the second decile, 179 in the ninth decile and 154 in the tenth decile. Across all three waves, 1197 families were identified as having a combined total of 2944 eligible individuals forming 2357 sib pairs.

\section{Approach and interview}

Prior to interview, individuals selected according to the above criteria were sent an approach letter explaining the purpose of the study and the procedures involved in study participation. We took advantage of this mailing to elicit extra phenotypic data by asking these individuals to complete an enclosed questionnaire that contained the Neuroticism and Extraversion scales (23items and 21 items respectively) of the Eysenck Personality Questionnaire $(E P Q)^{8}$ and return it in a reply-paid envelope. 
Interviewers then telephoned prospective participants to gauge interest in participation and arrange a convenient time for the interview. Before each interview started, subjects were asked to give verbal permission to audiotape the interview and, if given, this question was then repeated with the audio tape recording. In order to minimise observer bias, interviewers were unaware of interviewees' scores on the initial selection variables throughout the study. For the same reason, assignment of interviewers to prospective participants was carefully arranged so that no two members of the same family were interviewed by the same person.

Interviewers employed for this study had prior experience in conducting telephone interviews of this type, and underwent a week-long training course in the use of the computer-based diagnostic interview. Our instrument of choice was the CIDI (Composite International Diagnostic Interview), which was developed as a collaborative project between the World Health Organisation and the US National Institutes of Health. We used a shortened version in this study which contained the following diagnostic sections:

- Social phobia

- Agoraphobia

- Generalized anxiety disorder

- Panic disorder

- Obsessive compulsive disorder

- Depression

- Dysthymia

These sections contained questions that enable psychiatric diagnoses of the above conditions to be made according to the criteria established in the DSM-IV (Diagnostic \& Statistical Manual, Version 4) and in ICD-10 (International Classification of Diseases, Version 10). Non-diagnostic information in the interview included the full Neuroticism and Extraversion scales from the Eysenck Personality Questionnaire ${ }^{8}$ and Kessler's Psychological Distress Scal e. ${ }^{24}$ The EPQ items were the same as those sent as a questionnaire with the approach letter some weeks previously. The Neuroticism and Extraversion items were presented in randomised order to reduce response set bias.

\section{Blood and buccal sample collection}

At interview, each interviewee was asked if they would be prepared to provide a blood sample. If verbal consent was given, a consent form and courier pack containing blood collection tubes $(3 \times 9 \mathrm{ml}$ EDTA vacutainers) and an information sheet were forwarded, with instructions to take the courier pack to a doctor or local pathology service. Individual blood collection tubes were barcoded with identification numbers. The information sheet advised the doctor or pathology service to collect $27 \mathrm{ml}$ of blood, which was to be returned by courier along with the signed and witnessed consent form. In order to obtain parental genotype information where possible (to augment IBD information for linkage anal ysis and enable TDT testing for association), one sibling in each sibship with at least one parent still alive was asked for permission to contact their parent(s) for the purposes of requesting blood samples.

When participants declined to provide a blood sample, they were encouraged instead to provide buccal swabs. If verbal consent for this procedure was obtained, a consent form and courier pack containing a buccal swab kit, instructions and an information sheet were forwarded. In the kit were three sterile nylon bristle brushes and three $1.5 \mathrm{ml}$ tubes containing STE buccal solution. Mouth swabs were to be made using a brush on three separate occasions in one day, and detailed instructions were provided on how to perform this correctly. The brush heads were then returned in the tubes of solution by overnight courier delivery al ong with the signed, witnessed consent form.

\section{Results \\ Interview participation}

Interviews were completed by 2470 individual s chosen according to the selection criteria, with 256 people declining to participate and 192 prospective subjects who were uncontactable. A further 27 individuals were not approached since their participation would not complete a sib pair (for example, if their only eligible sibling had declined to participate), resulting in an interview success rate of $90.6 \%$ of those approached. Telephone interviews typically lasted approximately 25 minutes, with durations ranging between 10 minutes and 2 hours. Average interview time was not uniform across the four selection groups, with means of 22, 25, 35 and 38 minutes for selection deciles $1,2,9$ and 10 respectively $(P<0.001)$. Over $90 \%$ of interviews took less than 50 minutes to complete.

A slight interview participation bias was observed with respect to the selection variables, with more refusals $(10.6 \%$ vs $8.4 \% ; P=0.028)$ among people with high Neuroticism scores on the short-scale EPQ-R (Waves 1 and 2) or high combined Neuroticism, Anxiety and Depression scores (Wave 3). When considered separately, this participation bias was significant in Wave $1(P=0.005)$ but not Waves 2 and $3(P=0.297$ and $P=0.167$ respectively $)$. 


\section{Blood/buccal sample provision}

Of the 2451 individual s interviewed, 2243 agreed to provide blood samples, and a further 169 interviewees were prepared to provide buccal swab samples. An additional 5 individuals unwilling to participate in the actual interview also agreed to donate blood samples, whilst 55 interviewed subjects declined to provide either blood or buccal sample. Of the people who agreed to give blood or buccal samples, 90.7\% (2192/2417) actually did so. In addition, 21 samples were voluntarily provided by people who were initially unwilling. In total, blood or buccal samples were provided by $90.1 \%$ $(2213 / 2456)$ of individuals who were asked at interview. Blood or buccal samples were also col- lected from a further 837 individuals who were not interviewed, but whose genotype data (as parents of probands) was potentially valuable for linkage and association analyses.

No significant difference in values of selection variables between those who returned blood samples and those who returned buccal samples was observed. However, the number of people providing buccal samples was very small (5\% of samples received), as participants were encouraged to provide blood samples. People who scored highly on the selection variables were less likely to provide either a blood or buccal sample (74\% participation among those with high selection scores vs $78 \%$ for low selection scores; $P=0.016$ ) al though this effect mostly arises from Wave 1 where the selection scores

Table 2 Correlations between Neuroticism scale scores collected in this interview-based study and those obtained in previous questionnaire-based studies, by age and sex. Number of individuals in each category is al so shown

\begin{tabular}{|c|c|c|c|c|c|c|c|c|c|}
\hline \multirow[b]{3}{*}{ Age in 1980} & \multicolumn{4}{|c|}{$\begin{array}{l}\text { Correlation between Neuroticism scores in } \\
\qquad 1980^{\mathrm{a}} \text { and } 1999^{\mathrm{b}}\end{array}$} & \multirow[b]{3}{*}{ Age in 1989} & \multicolumn{4}{|c|}{$\begin{array}{l}\text { Correlation between Neuroticism scores in } \\
\qquad 1989^{c} \text { and } 1999^{b}\end{array}$} \\
\hline & \multicolumn{2}{|c|}{ Females } & \multicolumn{2}{|c|}{ Males } & & \multicolumn{2}{|c|}{ Females } & \multicolumn{2}{|c|}{ Males } \\
\hline & $r$ & $\mathrm{~N}$ & $r$ & $\mathrm{~N}$ & & $r$ & $\mathrm{~N}$ & $r$ & $\mathrm{~N}$ \\
\hline$<20$ & 0.57 & 55 & 0.59 & 32 & $<20$ & 0.53 & 52 & 0.73 & 27 \\
\hline $20-29$ & 0.71 & 244 & 0.67 & 142 & $20-29$ & 0.69 & 590 & 0.66 & 366 \\
\hline $30-39$ & 0.72 & 152 & 0.76 & 56 & $30-39$ & 0.73 & 451 & 0.76 & 314 \\
\hline $40-49$ & 0.85 & 50 & 0.85 & 21 & $40-49$ & 0.80 & 232 & 0.72 & 141 \\
\hline $50-59$ & 0.80 & 42 & 0.81 & 11 & $50-59$ & 0.87 & 83 & 0.82 & 45 \\
\hline $60+$ & 0.70 & 7 & - & - & $60+$ & 0.81 & 53 & 0.65 & 21 \\
\hline
\end{tabular}

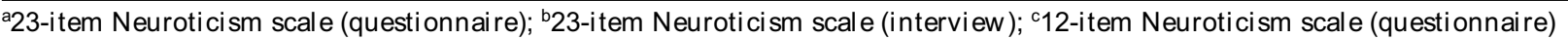

Table 3 Prevalences of various neuropsychiatric disorders in selected sample according to DSM-IV diagnosis criteria, with P-values for chi-square tests of homogeneity for low selection scores (deciles 1 and 2) vs high selection scores (deciles 9 and 10)

\begin{tabular}{|c|c|c|c|c|c|c|c|c|c|c|c|c|}
\hline DSM-IV diagnosis & Overall & $\begin{array}{l}\text { Decile } 1 \\
n=596\end{array}$ & $\begin{array}{l}\text { Females } \\
\text { Decile } 2 \\
n=256\end{array}$ & $\begin{array}{l}\text { (\%) } \\
\text { Decile } 9 \\
n=243\end{array}$ & $\begin{array}{l}\text { Decile } 10 \\
n=433\end{array}$ & $P$ value & Overall & $\begin{array}{l}\text { Decile } 1 \\
n=308\end{array}$ & $\begin{array}{l}\text { Mal } \\
\text { Decile } 2 \\
n=187\end{array}$ & $\begin{array}{l}\text { es }(\%) \\
n=145\end{array}$ & $\begin{array}{l}\text { Decile } 10 \\
n=302\end{array}$ & $P$ value \\
\hline Depression & 25.9 & 12.9 & 16.4 & 35.8 & 44.1 & $<0.001$ & 21.2 & 8.8 & 14.4 & 31.0 & 33.4 & $<0.001$ \\
\hline Dysthymia & 1.0 & 0.3 & 0 & 1.6 & 2.1 & $<0.001$ & 0.2 & 0 & 0 & 0 & 0.7 & 0.136 \\
\hline OCD & 4.9 & 1.7 & 0.8 & 4.9 & 11.5 & $<0.001^{\prime}$ & 6.1 & 1.9 & 1.1 & 9.7 & 11.6 & $<0.001$ \\
\hline $\begin{array}{l}\text { Panic disorder } \\
\text { without agoraphobia }\end{array}$ & 2.5 & 1.2 & 1.6 & 3.7 & 4.4 & $<0.001$ & 1.6 & 0.3 & 0.5 & 2.8 & 3.0 & 0.002 \\
\hline $\begin{array}{l}\text { Panic disorder } \\
\text { with agoraphobia }\end{array}$ & 1.3 & 0.5 & 0.4 & 2.1 & 2.5 & 0.001 & 1.3 & 0 & 0 & 2.8 & 2.6 & 0.001 \\
\hline $\begin{array}{l}\text { Agoraphobia without } \\
\text { panic disorder }\end{array}$ & 2.2 & 1.0 & 0 & 2.5 & 5.1 & $<0.001$ & 0.8 & 0.3 & 0.5 & 0.7 & 1.7 & 0.117 \\
\hline Social phobia & 6.2 & 1.7 & 3.1 & 7.0 & 13.9 & $<0.001$ & 6.8 & 1.0 & 2.7 & 10.3 & 13.6 & $<0.001$ \\
\hline $\begin{array}{l}\text { Generalised anxiety } \\
\text { disorder }\end{array}$ & 1.3 & 1.0 & 1.2 & 2.5 & 1.2 & 0.329 & 0.8 & 0 & 0 & 1.4 & 2.0 & 0.003 \\
\hline
\end{tabular}

Table4 Means in selected sample, with P-values for t-test for differences in mean scores

\begin{tabular}{|c|c|c|c|c|c|c|}
\hline & \multicolumn{3}{|c|}{ Females (mean \pm standard deviation) } & \multicolumn{3}{|c|}{ Males (mean \pm standard deviation) } \\
\hline & Decile 1, 2 & Decile 9, 10 & P-value & Decile 1, 2 & Decile 9, 10 & P-value \\
\hline Interview & $\mathrm{n}=851$ & $n=676$ & & $\mathrm{n}=495$ & $\mathrm{n}=447$ & \\
\hline EPQ Neuroticism (23 items) & $3.4 \pm 3.6$ & $12.1 \pm 5.7$ & $<0.001$ & $2.5 \pm 3.1$ & $10.6 \pm 5.7$ & $<0.001$ \\
\hline EPQ Extraversion (21 items) & $14.7 \pm 5.0$ & $11.6 \pm 5.6$ & $<0.001$ & $14.6 \pm 5.0$ & $11.8 \pm 5.6$ & $<0.001$ \\
\hline Kessler's Psychological distress scale & $47.6 \pm 3.7$ & $42.7 \pm 6.7$ & $<0.001$ & $47.6 \pm 2.9$ & $43.1 \pm 6.3$ & $<0.001$ \\
\hline Mailed questionnaire & $\mathrm{n}=760$ & $\mathrm{n}=600$ & & $n=417$ & $n=338$ & \\
\hline EPQ Neuroticism (23 items) & $4.2 \pm 4.1$ & $13.9 \pm 5.5$ & $<0.001$ & $2.9 \pm 3.4$ & $12.3 \pm 5.5$ & $<0.001$ \\
\hline EPQ Extraversion (21 items) & $13.7 \pm 5.1$ & $10.6 \pm 5.3$ & $<0.001$ & $13.7 \pm 5.1$ & $10.5 \pm 5.4$ & $<0.001$ \\
\hline
\end{tabular}



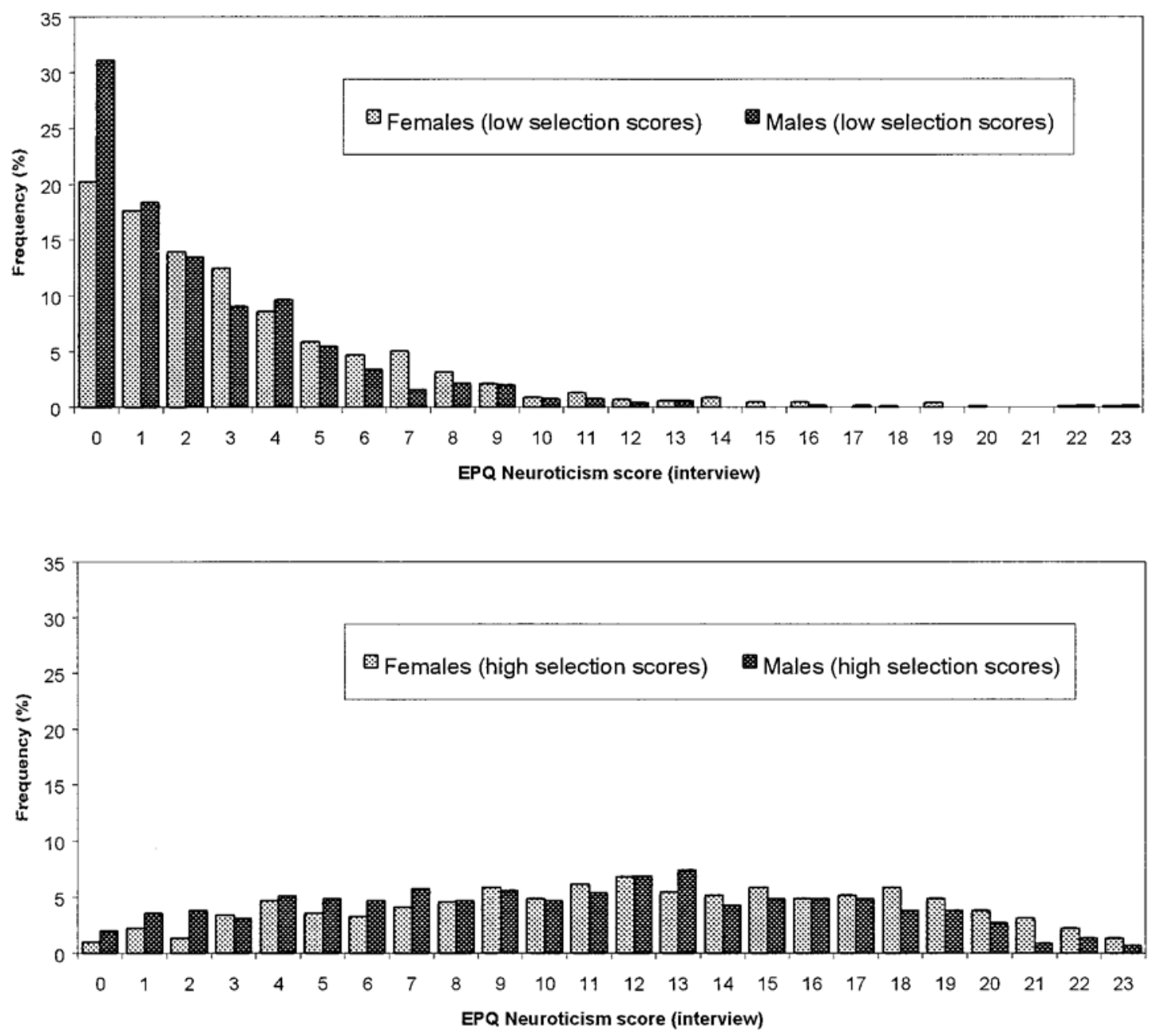

Figure2 Frequency distribution of EPQ Neuroticism scores (CIDI interview) by sex and original selection scores

for each group were in general more extreme $(70 \%$ for high selection scores vs $80 \%$ for low selection scores; $\mathrm{P}<0.001$ ).

Comparison of mailed questionnaire and telephone-administered EPQ scale scores

A total of 2055 individuals participated in the telephone interview and returned the questionnaire that was included with the approach letter, although missing responses to some items reduced the number of viable scores obtained from the questionnaire. Correlations between the scale scores obtained by questionnaire and interview exceeded 0.91 for both the Neuroticism $(\mathrm{N}=2046)$ and Extraversion $(N=2021)$ scales, with no significant difference between sexes. Small but statistically significant differences in scores were observed between the two methods, with scores obtained by mailed questionnaire higher than those obtained by telephone interview for the Neuroticism scale (mean difference $=1.2, \mathrm{P}<0.0001$ ) but lower for the Extraversion scale (mean difference $=0.2, P<0.0001$ ). Correlations between the telephone interview-based Neuroticism scores and scores obtained in previous questionnaire studies are shown in Table2, by age and sex. In total 415 individuals who participated in the interview did not return the questionnaire version of the EPQ Neuroticism and Extraversion scales. This group of people recorded a slightly higher mean Neuroticism scale score at interview compared to those who also returned the questionnaire form (7.5 vs 6.8; $P=0.03$ ).

Comparison of Composite International Diagnostic Interview (CIDI) results and selection scores

Responses to the items in the CIDI were analysed in order to determine individual diagnoses for the traits of interest according to DSM-IV criteria, and to 

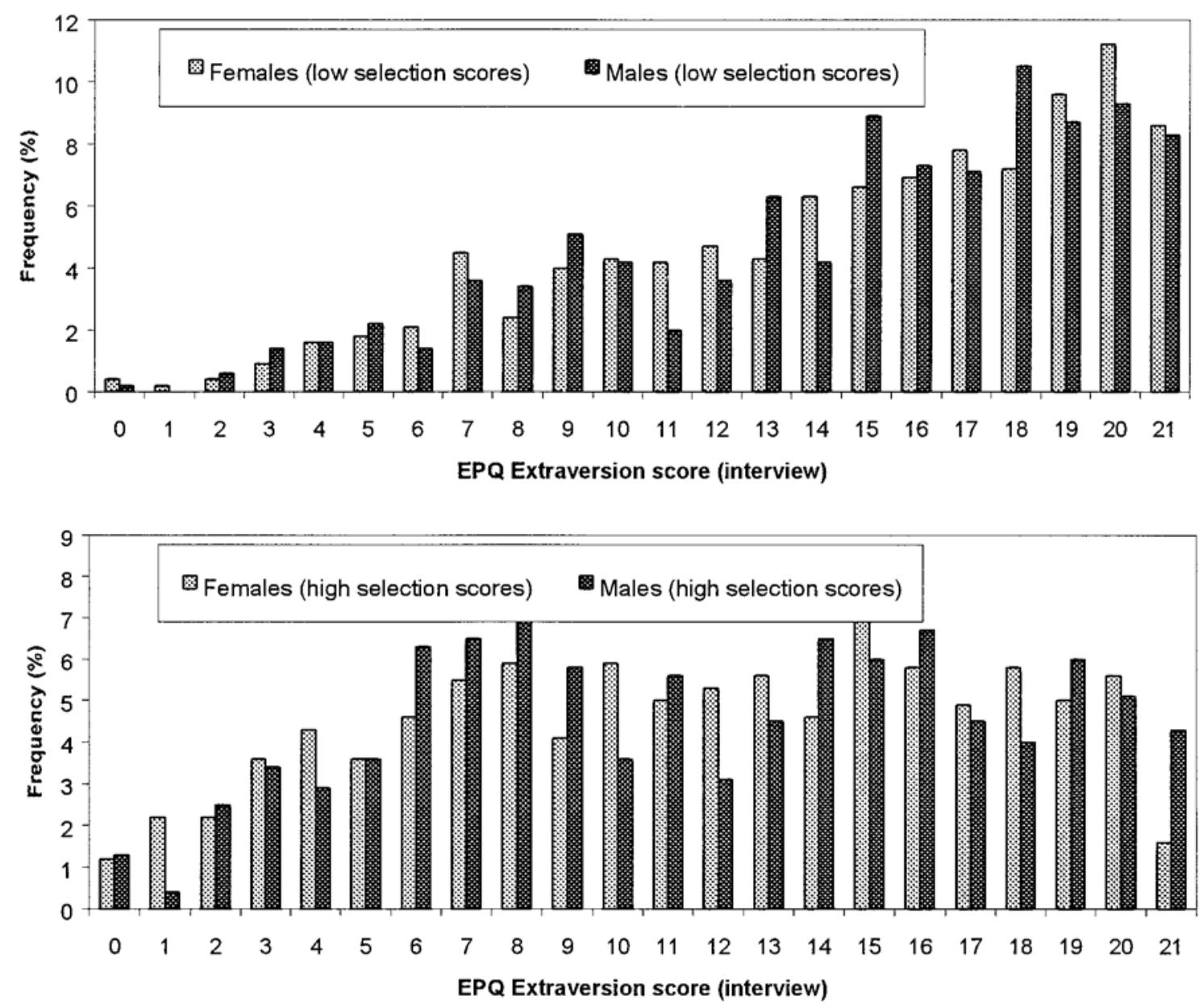

Figure3 Frequency distribution of EPQ Extraversion scores (CIDI interview) by sex and original selection scores

calculate total cumulative symptom scores for psychological scales. Of the 2473 individuals interviewed, $761(30.8 \%)$ were diagnosed according to DSM-IV criteria as affected by one or more of the disorders of interest.

Table 3 lists the preval ences in the sel ected sample of a range of neuropsychiatric disorders diagnosable from the CIDI interview according to DSM-IV diagnosis criteria. Prevalences are al so given separately for the groups of individuals with low (deciles 1 and 2 ) and high (deciles 9 and 10) scores on the sel ection variables. Chi-square tests of homogeneity were used to determine whether the prevalences of the various disorders differed between those with low and high selection scores. In most cases these were highly significant for both sexes, with diagnoses for most disorders over 2.5 times as common in the group with high selection scores. For the more common disorders in the sample (eg depression, OCD and social phobia), it can also be seen that the various prevalences increase monotonically with selection score across all four decile groups. However, there is low power to detect such effects for disorders with low prevalence.

A comparison of scores for the non-diagnostic psychological scales included in the interview (Neuroticism and Extraversion scales from the mailed and interview versions of the EPQ, and Kessler's Psychological Distress Scale) is shown in Table4. Frequency distributions for the various scal es by sex and selection score are shown in Figures 2-4 (results for mailed questionnaire versions of the EPQ Extraversion and Neuroticism scales were extremely similar to those obtained by interview, and are thus not shown graphically). Scores obtained on the full (23-item) EPQ Neuroticism scale are substantially correlated with those obtained on the short (12-item) version of the Neuroticism scale in self-administered questionnaires between 5 and 18 years previously. Those with low selection scores are much more likely to have low Neuroticism scores for both questionnaire and interview, while the distribution of Neuroticism scores is much more uniform for those with high selection scores (Figure2). Smaller 

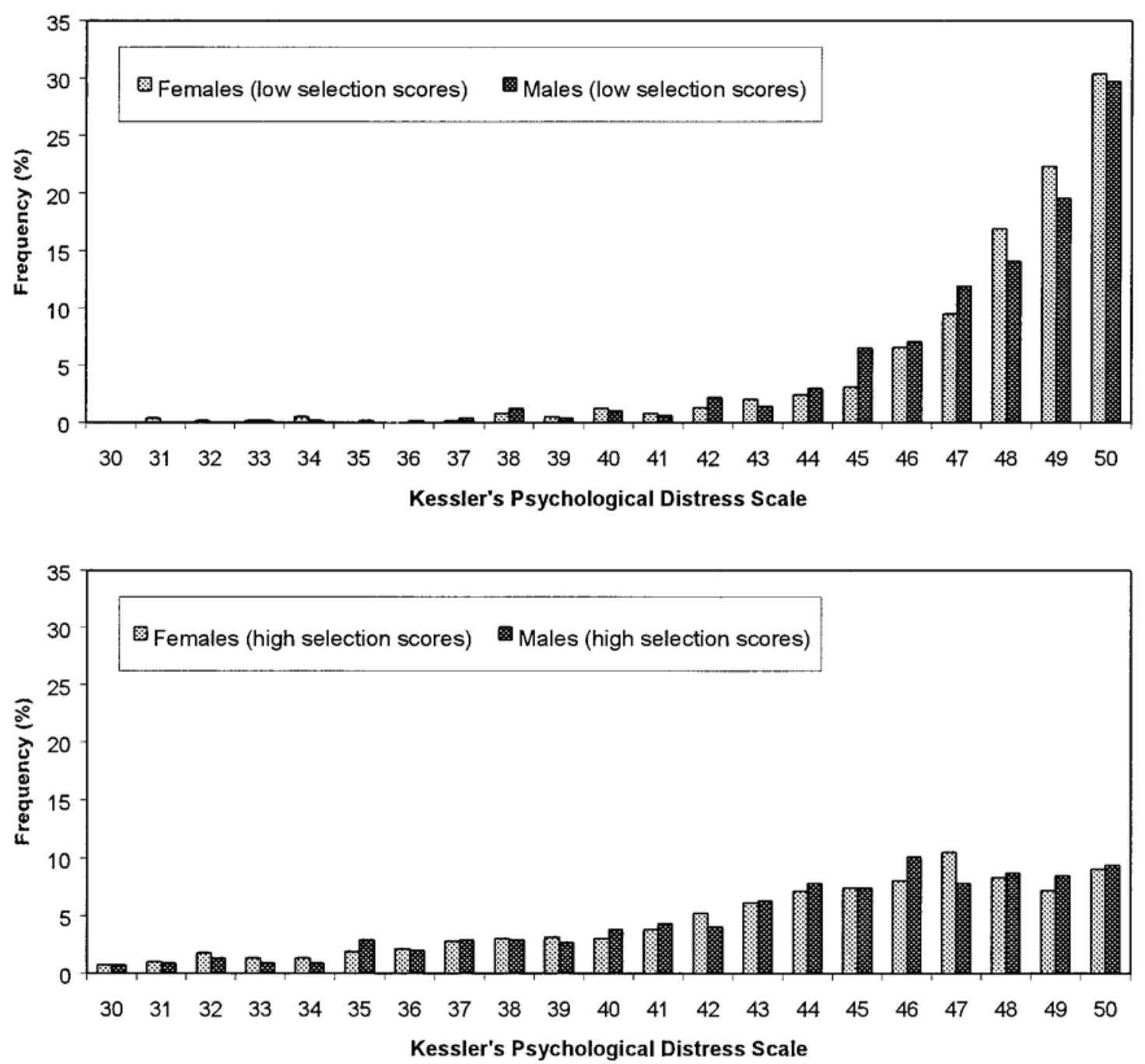

Figure4 Frequency distribution of Kessler's Psychological Distress Scale scores (CIDI interview) by sex and original selection scores

effects are observed for Extraversion, with low selection scores predicting slightly higher Extraversion scores (Figure 3). Low sel ection scores were al so associated with lower psychological distress as measured by Kessler's Psychological Distress scale, which is scored in the reverse direction (Figure4).

\section{Discussion}

Prevalence rates for all the neuropsychiatric disorders in this interview study were higher in those with high selection scores (based on self-report questionnaire responses given on average 10 years earlier) than in those with low selection scores. For most of the variables of interest, these differences were statistically significant, with prevalences in the upper selection quintile 2 to 9 times higher than the lowest quintile. These differences indicate the efficiency of using related measures (even those obtained some 10 years previously) to sel ect individuals, and provide early support for our basic hypothesis that the phenotypes of interest are at least partly underpinned by a common factor, although more extensive analysis will be required to confirm its nature. For the non-diagnostic continuous measures (EPQ Neuroticism and Extraversion; Kessler's Psychological Distress Scale), response distributions differed substantially between those with low and high selection scores. Those with low selection scores tended to be concentrated towards one end of the range, while those with high selection scores were observed to follow more uniform distributions. This suggests that, for these continuous measures, the selection procedure is more suited to predicting those who will achieve low scores at later time points, rather than high scores. 
For some disorders, the prevalence rates in this sample differ from generally recognised values for the Australian population, even allowing for the enrichment of the sample. Those apparently meeting OCD criteria, for example, are even more numerous than would be expected, and the prevalences of dysthymia and generalised anxiety disorder are low. These variations may reflect an interaction between disorder and compliance with a multiwave study, in that continued participation feels right to people with OCD and onerous to people with dysthymia and GAD.

Some participation bias was observed in this study, both in the interview phase and for the donation of blood or buccal samples, with individuals scoring highly for neuroticism, anxiety and depression measures less likely to agree to full involvement in the study. It should be noted that the decile rankings on which individuals were selected for this study are based on the scale scores of the twin pairs and their relatives who had previously participated in at least one Health and Lifestyle questionnaire study. If a similar participation bias influenced the initial sample from which the subjects in this study were ascertained, these decile rankings may be somewhat biased downwards, and not completely reflect the true distribution of scale scores in the Australian population.

Our procedure is inferior to that used by Boomsma and colleagues (see this issue) who estimate genetic factor scores using all available measures and base their selection entirely on these. This method requires considerable preliminary work and is computationally intensive. Practical considerations dictated that we use a method which was much simpler and quick to implement, and we suspect is only slightly less efficient at identifying the most genetically informative subjects.

\section{Acknowledgements}

This study was approved by the Bancroft Research Ethics Committee. We thank Lorna Peters for her role in preparing the CIDI computer-driven telephone interview and the scoring algorithm; our interviewers and clerical and administrative support staff, Jhn Pearson and Olivia Zheng for computer support, and our laboratory staff. We also thank Dr Lindon Eaves for helpful discussions and advice on the selection scheme. Most of all we thank the twins and their relatives for their willing participation. We acknowledge the role of $\mathrm{Dr}$ Andrew Heath and $\mathrm{NIH}$ grants (AA07535 and AA 07728) in earlier projects in which selection variables were collected. This study was funded by the Australian National Health and
Medical Research Council (971232) and Gemini Genomics Plc.

\section{References}

1 Jardine R, Martin NG, Henderson AS. Genetic covariation between neuroticism and the symptoms of anxiety and depression. Genet Epidemiol 1984; 1: 89-107.

2 Kendler K, Heath A, Martin N, Eaves LJ. Symptoms of anxiety and depression in a volunteer twin population. The etiologic role of genetic and environmental factors. Arch Gen Psychiatry 1986; 43: 213-221.

3 Kendler KS, Heath AC, Martin NG, Eaves LJ. Symptoms of anxiety and symptoms of depression. Same genes, different environments? Arch Gen Psychiatry 1987; 44: 451-457.

4 Kendler KS, Neale MC, Kessler RC, Heath AC, Eaves LJ. Major depression and generalized anxiety disorder. Same genes (partly) different environments? Arch Gen Psychiatry 1992; 44: 451-457.

5 Roy MA, Neale MC, Pedersen NL, Mathe AA, Kendler KS. A twin study of generalized anxiety disorder and major depression. Psychol Med 1995; 23: 1037-1049.

6 Kendler KS. Major depression and generalized anxiety disorder. Same genes, (partly) different environments - revisited. Br J Psychiatry 1996; 30: 68-75.

7 Eley TC, Stevenson J. Exploring the covariation between anxiety and depression symptoms: a genetic analysis of the effects of age and sex. J Child Psychol Psychiatry 1999; 40: 1273-1282.

8 Eysenck HJ, Eysenck SBG. Manual of the Eysenck Personality Questionnaire. Hodder and Stoughton: London, 1975.

9 Hickie I, Kirk KM, Martin NG. Unique genetic and environmental determinants of prolonged fatigue: a twin study. Psychol Med 1999; 29: 259-268.

10 Kendler KS, Karkowski LM, Prescott CA. Fears and phobias: reliability and heritability. Psychol Med 1999; 29: 539-553.

11 Martin NG, Jardine R, Andrews G, Heath AC. Anxiety disorders and neuroticism: are there genetic factors specific to panic? Acta Psychiatr Scand 1988; 77: 698-706.

12 Kendler KS, Walters EE, Neale MC, Kessler RC, Heath AC, Eaves LJ. The structure of the genetic and environmental risk factors for six major psychiatric disorders in women. Phobia, generalized anxiety disorder, panic disorder, bulimia, major depression, and alcoholism. Arch Gen Psychiatry 1995; 52: 374-383.

13 Scherrer F, True WR, Xian H, Lyons MJ, Eisen SA, Goldberg J, Lin N, Tsuang MT. Evidence for genetic influences common and specific to symptoms of generalized anxiety and panic. J Affect Disord 2000; 57: 25-35.

14 Kendler KS, Karkowski-Shuman L. Stressful life events and genetic liability to major depression: genetic control of exposure to the environment? Psychol Med 1997; 27: 539-547.

15 Eaves LJ, Meyer J. Locating human quantitative trait loci: guidelines for the selection of sibling pairs for genotyping. Behav Genet 1994; 24: 443-456.

16 Risch N, Zhang H. Extreme discordant sib pairs for mapping quantitative trait Ioci in humans. Science 1995; 268: 1584-1589.

17 Gu C, Todorov A, Rao DC. Combining extremely concordant sibpairs with extremely discordant sibpairs provides a cost effective way to linkage analysis of quantitative trait loci. Genet Epidemiol 1996; 13: 513-533.

18 Bedford A, Foulds GA, Sheffield BF. A new personal disturbance scale (DSSI/SAD). Br J Soc Clin Psychol 1976; 15: 387-394. 
19 Eysenck SBG, Eysenck HJ, Barrett P. A revised version of the psychoticism scale. Pers Individ Diff 1985; 6: 21-29.

20 Derogatis LR, Lipman RS, Covi L. SCL-90: an outpatient psychiatric rating scale - preliminary report. Psychopharmacol Bull 1973; 9: 13-28.

21 Gillespie N, Kirk KM, Heath AC, Martin NG, Hickie I. Somatic distress as a distinct psychological dimension. Soc Psychiatry Psychiatr Epidemiol 1999; 34: 451-458.
22 Carey G, Williamson J. Linkage analysis of quantitative traits: increased power by using selected samples. Am JHum Genet 1991; 49: 786-796.

23 Lake RIE. Aspects of the Genetic Architecture of Neuroticism. PhD thesis, University of Queensland, 1999.

24 Kessler R, Mroczek D. Final version of the Psychological Distress Scale. Technical Note. Institute for Social Research, University of Michigan, Ann Arbor, MI, 1994. 